\title{
Entrevista: Gersem José dos Santos Luciano - Gersem Baniwa
}

Pelotas (RS), 15 de maio de 2012, durante 0 II Fórum Internacional da Temática Indígena

Maria Aparecida Bergamaschi*

Gersem José dos Santos Luciano é doutor em Antropologia Social pela Universidade de Brasília (UnB), Baniwa, nascido na aldeia Yaquirana, no Alto Rio Negro, Amazonas. Professor indígena, integrou o Conselho Nacional de Educação (CNE) e esteve à frente da Coordenação da Educação Escolar Indígena, no Ministério da Educação (Secad/MEC).

Vamos começar nossa conversa pedindo que faças uma breve apresentação da tua trajetória de formação e atuação na área de educação escolar indígena.

O meu primeiro contato com a escola foi com missionários, com a escola colonizadora, propriamente dita: era uma escola para educar, civilizar e domesticar os índios numa época em que o objetivo da escola para os índios era isso: pacificar para integrar. A escola era para domesticar a nova geração de indígenas para se tornarem pessoas e cidadãos obedientes às imposições do Estado. Por outro lado tive a oportunidade de frequentar, do ponto de vista colonial, boas escolas que são as escolas salesianas. A região do Alto Rio Negro sempre teve forte presença dos missionários salesianos com suas escolas, e isso me permitiu estudar até o Ensino Médio nessas escolas. São escolas muito boas, do ponto de vista da escola tradicional branca.

Depois, a segunda experiência foi com a discussão e experimentação de tentativas de mudança dessa escola tradicional colonial para uma escola que pudesse principalmente reconhecer, respeitar e valorizar os conhecimentos, as tradições, os valores e os conhecimentos indígenas. A grande diferença, em minha opinião, da escola colonial tradicional e da escola hoje pretendida pelos

*Faculdade de Educação, Universidade Federal do Rio Grande do Sul. Av. Paulo Gama, 110. 90040-060 Porto Alegre - RS - Brasil. cida.bergamaschi@gmail.com 
povos indígenas é isso, que a escola indígena respeite e valorize também os conhecimentos e as culturas indígenas. Não está em discussão a importância do acesso aos conhecimentos da escola tradicional, o que se quer é a valorização dos dois saberes, indígena e não indígena, no mesmo nível de importância.

A outra experiência foi no campo da política pública, ainda muito cedo. Assim que terminei a Graduação na Universidade Federal do Amazonas (UFAM), atuei 3 anos como secretário de Educação do município de São Gabriel da Cachoeira (AM), entre 1997 e 1999. Eu era muito jovem, pouco entendia e pouco conhecia o ambiente da política governamental. O que eu sabia e queria eram basicamente duas coisas: uma, que era muito estranha aquela escola que existia na época na região, que proibia as línguas indígenas, as tradições e os conhecimentos dos povos indígenas. Essa escola perseguia os velhos pajés e os sábios indígenas. Outra coisa que sabia era a necessidade de mudar aos poucos essa escola. Foi com esses objetivos e sentido que atuei. Foi uma grande aprendizagem e também grande desafio de transformar as escolas rurais, como eram chamadas as escolas implantadas nas aldeias com o currículo colonial, integracionista e perseguidor dos conhecimentos e culturas indígenas, para escolas indígenas autogeridas, com currículos interculturais e bilíngues. Para isso inicialmente tivemos que elaborar e aprovar todo o arcabouço legal e normativo educacional do município, para depois iniciarmos as mudanças curriculares, pedagógicas e de gestão das escolas indígenas.

Os 4 anos na Secretaria de Educação foram fundamentais para os compromissos posteriores. Nós mudamos totalmente a diretriz política do município, que era um município comum, com leis seguindo as diretrizes e as políticas nacionais, sem nenhuma diferenciação para os povos indígenas, que representam $90 \%$ da população do município. Durante os 4 anos à frente da Secretaria de Educação do município, conseguimos mudar todo o arcabouço legal para possibilitar a construção de escolas diferenciadas. Escolas que não proibissem mais as línguas e que passassem a valorizar os conhecimentos indígenas. Começou-se a discutir material didático específico nas línguas indígenas, isso numa época em que, mesmo na academia, esse tema era muito pouco discutido. Pouca gente se dedicava a esses temas e não tinha literatura: nossa missão era uma espécie de aventura.

O retorno para a aldeia, depois dessa experiência, foi para experimentar isso na prática, o que foi muito interessante porque ao mudar o arcabouço 
político e jurídico do município, achava que era muito simples de implementar. Fomos verificar que não é bem assim: primeiro, porque não é fácil do ponto de vista técnico e pedagógico. Todo o processo colonial tinha formado a cabeça dos próprios indígenas a gostar daquele modelo de escola colonial, e desconfiavam desse novo discurso de escola indígena, de escola valorizando os conhecimentos, as tradições. Era muito comum ouvir: "Não, mas para que a gente vai tratar da nossa língua na escola, nós já falamos a língua. Queremos aprender o inglês, o espanhol, o português" e assim por diante. Dessa maneira eu sempre tive uma posição muito equilibrada com relação à necessidade das mudanças - sempre acreditei e atuei nessa perspectiva -, mas respeitando os tempos, inclusive, considerando o processo longo de colonização, de imposição de visão de mundo, além das pedagogias dos colonizadores que acabaram de alguma maneira sufocando as pedagogias indígenas.

Depois disso, continuei atuando junto com o poder público, em algumas políticas públicas, não só com a educação, mas atuei algum tempo com projetos comunitários, projetos de desenvolvimento e de sustentabilidade ou simplesmente projetos comunitários alternativos para comunidades indígenas. Assim fui percebendo o outro lado das questões e dos desafios da luta indígena, que me levaram para o campo das universidades: graduação e pós-graduação. Atuando na esfera da política pública, senti muita necessidade das ferramentas técnicas e teóricas, não só para estabelecer um diálogo com os técnicos, os gestores e os dirigentes da administração pública, mas também para dar conta da tarefa técnica e administrativa. Entre 2000 e 2004, por indicação do movimento indígena amazônico, coordenei uma complexa tarefa de conceber, estruturar e organizar uma linha de financiamento para as comunidades e organizações indígenas no âmbito do Ministério do Meio Ambiente, que foi o Projeto Demonstrativo dos Povos Indígenas (PDPI/MMA), que exigiu um conhecimento do mundo não indígena na área técnica para cumprir essa missão. O PDPI foi um projeto negociado pelo movimento social indígena por ocasião da Conferência Mundial do Meio Ambiente, a RIO-92 ou ECO-92, para apoiar e estimular iniciativas inovadoras no campo do desenvolvimento autossustentável das comunidades indígenas da Amazônia Brasileira, que contou com apoio técnico e financeiro do G7 (Grupo dos sete países mais ricos do mundo), sob a coordenação do Ministério do Meio Ambiente do Brasil. E foi 
em função dessa necessidade que eu fui parar na universidade, fazendo graduação e pós-graduação.

Resumindo um pouco a minha experiência com a escola, por um lado, parti da experiência da escola stricto sensu colonial, aquela escola bem tradicional, branca, mas sempre com essa visão de que teria que ser feita alguma mudança para dar lugar e espaço aos conhecimentos, aos valores e às realidades indígenas. Minha atuação foi muito forte no campo de políticas públicas, por isso a minha visão tem a ver com a necessidade dos índios aproveitarem as coisas boas da escola e da universidade para estabelecer uma relação menos assimétrica com a sociedade dominante e construir correlações de forças menos desiguais. A possibilidade da defesa e do avanço dos direitos indígenas hoje tem muito a ver com tudo isso. Esse é um pouco o meu perfil, e é dessa forma que procuro contribuir com os atuais processos de discussões e de construção de políticas públicas no campo da educação escolar indígena.

\section{É essa trajetória que te leva para o Ministério da Educação?}

Em função dessa experiência fui parar no Ministério da Educação. Primeiro no Conselho Nacional de Educação (CNE) pela necessidade de implementar as orientações normativas do CNE para as escolas indígenas. Fiquei 2 anos no CNE e foi uma experiência importante, não pelo que deu para fazer em 2 anos, mas como oportunidade de conhecer como funciona, o que pensa a elite pensante da educação brasileira. Isso para mim foi fundamental. A gente só pode entender os desafios da educação brasileira e particularmente da educação indígena, que se propõe ser alternativa, ser diferente, mas que enfrenta enormes dificuldades e limitações, se entendermos como a elite brasileira (da educação) pensa a educação no Brasil, quais são suas orientações e suas visões.

O CNE é um laboratório de diversidades de pensamento, pois são 24 conselheiros e eu era um deles, mas apresenta certa hegemonia de pensamento em alguns aspectos, como por exemplo, na defesa do universalismo das políticas públicas, para não pôr em questionamento a unidade nacional ou soberania nacional. Porém, isso não é para gerar pessimismo, muito menos tristeza, ou ainda pensar que é tão difícil o trabalho com a educação escolar indígena, só porque os intelectuais e pensadores não indígenas não vão permitir ou colaborar. Pelo contrário, são desafios que nos estimulam a pensar e organizar estratégias mais eficientes na construção das políticas inovadoras. A partir 
dessa atuação fui parar na Coordenação Geral da Educação Escolar Indígena do Ministério da Educação com objetivo de discutir e organizar uma agenda de trabalho que pudesse viabilizar passos necessários rumo a uma política de educação escolar indígena mais próxima dos desejos das comunidades indígenas. Foi um momento em que o movimento indígena estava muito inquieto, porque mesmo com as conquistas da Constituição de 1988 relativas ao direito à educação própria e à educação diferenciada, depois de passados 15 anos, pouco havia mudado na prática das escolas. O desafio era pensar instrumentos administrativos e pedagógicos que pudessem facilitar e avançar na efetivação desses direitos. Para organizar e estruturar esses instrumentos tomamos a decisão de fazer isso ouvindo e envolvendo os povos indígenas, por isso nossa primeira medida tomada foi organizar e realizar a I Primeira Conferência Nacional de Educação Escolar Indígena (I CONEEI), com a participação direta das escolas-comunidades por meio das conferências locais e regionais, e finalmente a conferência nacional. A Conferência definiu claramente a agenda nacional para a política nacional de educação escolar indígena, cuja primeira fase seria a implantação dos Territórios Etnoeducacionais, como uma nova referência espacial e institucional das políticas, dos programas e das ações do Estado, e como meta final o estabelecimento de um Sistema Próprio de Educação Escolar Indígena, capaz de garantir a implementação das escolas indígenas diferenciadas e autônomas.

Esses foram os desafios enfrentados durante os 4 anos de trabalho no MEC e que foram muito importantes para perceber as possibilidades e limitações das políticas públicas no campo da educação escolar indígena e que permitiram chegar a algumas conclusões muito relevantes para, de novo, voltar ao movimento indígena e pensar como desobstruir essas dificuldades.

A trajetória escolar para mim sempre foi estratégica, desde a escola da aldeia. Depois tentei avançar com essas experiências nas políticas públicas de modo mais geral. Sempre tentei colaborar com a organização e a estruturação legal e administrativa da política de educação escolar indígena, ao mesmo tempo ou intercaladamente voltar para a aldeia e experimentar na prática os novos ideais, as novas orientações e as normas renovadas. Ou seja, pensando as políticas muitas vezes como gestor, auxiliando na gestão dessas políticas, mas também, em tempos intercalados, ir a campo e à escola indígena para viver a prática. Eu acho que isso é fundamental. Eu acho, por exemplo, que os 
pensadores na academia e os gestores e técnicos governamentais deveriam fazer isso, e nem todos o fazem. Sei que muitas pessoas da área de antropologia também iniciam estudando teorias e depois vão a campo, onde passam a conviver com os índios para conhecer e experimentar a vida indígena e comprovar ou negar suas teorias, ideais e hipóteses. Porque muitas vezes é muito simples e cômodo imaginar, pensar, supor como são as coisas de fato. Outra coisa é quando você pensa transformar essas ideias em ações concretas, numa aldeia e numa escola indígena real.

Como enxergas o panorama da educação indígena hoje no Brasil - que de alguma forma já apresentas? Como avalia as possibilidades para essa educação e como se articula à educação escolar? Uma coisa é a escola indígena e outra a educação indígena, a educação ameríndia, diferenças que apontas na tua fala.

Em termos de panorama da educação indígena eu não diria que é um panorama desolador. A educação tradicional sofreu abalos e perdas muito grandes no processo de colonização por meio da escola colonial. Mas muitas culturas, conhecimentos, valores e pedagogias indígenas continuam existindo, operando e garantindo a continuidade histórica dos povos indígenas, como povos cultural e etnicamente diferenciados. No entanto, é importante reconhecer que muitas culturas, conhecimentos e valores indígenas se perderam por imposição da escola.

O esforço hoje é para que a escola não faça mais isso, e, ao contrário, passe a contribuir com a valorização e perpetuação dos modos próprios de educação dos povos indígenas, e já podemos observar resultados muito positivos, como a valorização das línguas indígenas, dos saberes orais dos mais velhos. Hoje as escolas pelo menos não proíbem e nem perseguem mais os conhecimentos, as culturas e as tradições indígenas. Isso já em si é um grande avanço. Mas, mesmo a escola não sendo mais negadora e perseguidora das culturas indígenas, ainda não é suficiente para recolocar o papel das pedagogias tradicionais no mesmo patamar das pedagogias escolares na vida das pessoas e coletividades indígenas. É um processo mais longo. O desafio da escola indígena atual é encontrar esse ponto de equilíbrio, valorizar os saberes indígenas no mesmo nível da valorização dos saberes científicos e tecnológicos, que em geral chamamos de educação intercultural. Mas isso não é apenas tarefa da escola, como 
instituição do Estado ainda que em mãos indígenas, mas principalmente da família, da comunidade e do povo indígena.

Penso que não é a escola que vai resolver a questão da educação tradicional ou da identidade indígena, nem é seu papel, embora deva dar sua contribuição. Um exercício que precisa ser feito é pensar a escola como instrumento de conexão da vida da aldeia com o mundo exterior e a família e o povo como responsáveis pela educação interna, como tem sido desde os primórdios da vida indígena, como dois espaços distintos, mas conectados, articulados e organicamente coordenados. Já no campo da educação escolar, entendo que nós tivemos de fato muitas conquistas, muitos avanços, mas nem sempre as comunidades indígenas conseguem enxergar os avanços, em várias direções. Uma delas, que eu já falei, é o avanço do direito. Nós temos um arcabouço de leis, de normas, de orientações pedagógicas que são muito avançadas, inclusive muito avançadas considerando o panorama da educação indígena no mundo ou, principalmente, na América Latina. A ampliação da oferta escolar junto às aldeias é outra conquista. A crescente produção de material didático específico e bilíngue e os processos crescentes de formação de professores indígenas, que já representam 96\% atuando nas escolas das aldeias, representam outros importantes avanços. Além disso, o surgimento de escolas indígenas razoavelmente autônomas em termos de gestão pedagógica e administrativa representa outra relevância estratégica, pois são elas que podem fazer a necessária e adequada conexão entre a educação escolar e a educação tradicional. Isso é uma conquista, não é uma dádiva. Foi o resultado de muita luta, de muita mobilização, de muito trabalho do movimento indígena e seus aliados e parceiros. A academia participou muito disso, pelo menos muita gente da academia, de diferentes campos, da educação, da antropologia, da sociologia.

Esse arcabouço jurídico e as experiências inovadoras de escolas indígenas são ferramentas importantes que precisamos reconhecer e valorizar muito, porque são conquistas. Porém, são conquistas que não estão garantidas, pois, em algum momento, podemos perdê-las no campo do direito, daí a necessidade de constante vigilância. Eu acho que tem outro avanço concreto, gerado a partir dessa legislação, que são as possibilidades de cada povo poder construir suas experiências de educação escolar. Isso também é uma coisa muito positiva, principalmente se levarmos em consideração que as escolas indígenas, do ponto de vista de recursos humanos, estão nas mãos dos índios. Isso porque na 
atualidade, 96\% de professores atuando nas escolas indígenas são indígenas, e a grande maioria dos gestores e técnicos também são indígenas. As escolas indígenas já não são mais de monopólio exclusivo dos brancos ou do governo. Cabe, portanto, aos índios se apropriarem dessas escolas, transformá-las e gerenciá-las segundo suas demandas e interesses, como instrumento de empoderamento, protagonismo e autonomia.

Nessa direção, já temos hoje no Brasil dezenas ou centenas de diferentes experiências, de modelos e de processos diferentes de construção e organização da escola indígena, com uma variedade enorme, nem sempre valorizada, sistematizada e divulgada. Essas experiências vão desde escolas razoavelmente autônomas, com pouco domínio ou orientação do poder público: experiências tocadas pelas comunidades indígenas. Até recentemente as escolas Yanomami não tinham o reconhecimento do Estado e, no entanto, funcionavam com sua lógica, com seu tempo, com sua organização curricular. Os professores não eram contratados, mas tinham apoio de algumas ONGs para desenvolverem seus trabalhos. E hoje eles têm escolas com padrões curriculares diferenciados, bancadas pelo poder público. Temos também um grande número de escolas que continuam seguindo um modelo clássico da escola tradicional e muitas vezes por desejo da comunidade indígena, e isso é legítimo.

Trabalhar com essa ideia da participação, do protagonismo, da democracia, da liberdade dos índios também requer coerência no reconhecimento de seu protagonismo como sujeitos de direitos e vontades legítimas que precisam ser respeitados, mesmo quando tomam decisões que contrariam o senso comum do politicamente correto. Nem sempre a escola que é vista muitas vezes como um modelo branco é uma coisa ruim. Às vezes não interessam outros modelos de escola, e muitas comunidades indígenas têm essa clareza. Essa é uma discussão que sempre travei dentro do MEC e no Brasil como um todo: a gente tem que parar de fazer essa avaliação, esse julgamento do ideal de uma escola indígena. Ninguém tem esse modelo, nem no pensamento, nem na ação. E nem os povos indígenas têm clareza disso ou não querem ter clareza disso. Cada comunidade indígena tem a sua escola, algumas com um viés mais tradicional, colonial, porque assim querem em um determinado tempo histórico. Em outro momento podem mudar de decisão e fazer outras escolhas que correspondam às suas realidades em constantes mudanças. Eu sempre ouvi de grandes lideranças indígenas com expressão nacional como Megaron 
Tchukarramãe Kayapó ou Paulinho Paiakan, que possuem largas experiências de lutas no Pará, quando a gente pergunta a eles, "O que vocês querem da escola?", "Para que vocês querem a escola?”, eles não vão demorar um segundo para responder com clareza e segurança: "Nós queremos a escola para ensinar nossos filhos falar português, aprender matemática, para poder dialogar com chefe branco, com os dirigentes brancos". Você não vai ouvir "nós queremos escola para ensinar nossa língua, nossa tradição". Essa diversidade é uma experiência grande que temos no Brasil e que cada vez mais vai se consolidando.

E se queremos falar de quantidade de avanços e conquistas, isso também é representativo, o poder público pode conseguir, para o bem ou para o mal, universalizar a oferta, formando e contratando professores, construindo escolas, oferecendo transporte escolar e produzindo e distribuindo material didático. Ainda com condições muito precárias, mas hoje dificilmente se encontra uma aldeia sem algum tipo de escola. Aqui me refiro ao processo educativo e não somente à escola, entendida como espaço físico, porque, curiosamente, um terço das escolas indígenas no Brasil não tem sede e muita gente diz: "Não, mas isso significa um péssimo quadro para a política brasileira". Nem sempre: Por que escola indígena tem que ter prédio?

Aliás, eu acho que a escola indígena não deveria ter prédio - prédio como nós pensamos, de alvenaria, que é isso que o poder público faz. Então, é bom ter muito cuidado com isso. Você imaginar que um terço das escolas não tem prédio e achar que isso é uma política péssima? Nem sempre. Oxalá se a inexistência desses prédios pudesse ser uma coisa positiva, porque os índios não queriam copiar o modelo, porque queriam um processo de educação mais dinâmico, que não precisasse ter um prédio, mas fazer isso na aldeia, aproveitando os espaços que a aldeia possui, espaços comunitários, espaços de cerimônias, ambientes de trabalho, da pescaria, da caça, do dia a dia, momentos dos rituais, dos contos que acontecem. Obviamente que também não dá para usar esse argumento para que o poder público não faça o que tem que fazer. Se a comunidade de fato opta e quer uma escola com infraestrutura boa ao modelo branco, é um direito, e o poder público tem que fazer. Não há discussão com relação a isso.

\section{Sem precarizar!}

Exatamente! O que não dá é para transformar a escola indígena em instituição precária, de segunda categoria. Tem algumas comunidades indígenas 
que de fato batalham para não ter os prédios físicos, como no modelo branco oferecido pelo poder público, principalmente pelo Ministério da Educação por meio do Fundo Nacional de Desenvolvimento da Educação (FNDE). Muitas vezes o discurso que se faz generaliza demais. Leva-se em consideração o número de escolas que não têm prédio para qualificar o nível da política. Isso de certa maneira vai forçando a própria visão indígena de que "se eu não tenho um prédio bonito é porque a minha escola não presta" ou que "a nossa educação não funciona e não presta". Os povos indígenas nunca construíram prédios para fazer ou ter educação, mas sempre tiveram boa educação, capaz de garantir suficiente sociabilidade e convivência de todos os indivíduos e grupos étnicos ao longo de milhares de anos. A ideia de prédio escolar como nota de avaliação da educação é questionável e acaba fazendo uma ingerência perversa, induzindo as comunidades indígenas a pensarem que o sinônimo de boa escola indígena é um prédio bonito, não importam os conteúdos, as pedagogias e as metodologias trabalhadas. E muitas vezes se esquece de discutir o processo e as experiências pedagógicas em si.

Eu diria que nós conseguimos avançar muito, principalmente na questão da oferta escolar, e, com isso, o direito está sendo consolidado na medida em que o poder público cada vez mais vem assumido seu papel. Agora, tem enormes desafios, desde infraestrutura, material didático, organização curricular, tempo curricular. Tem um enorme conservadorismo na política pública como tal e, sem dúvida, de difícil solução. Há uma resistência muito grande do sistema nacional, dos sistemas estaduais, dos sistemas municipais em fazer o seu papel técnico, administrativo, jurídico, político, normativo, em reconhecer as diversas experiências inovadoras de escolas indígenas. Isso é real. É importante reconhecer as limitações e os problemas da administração e da política pública estatal que é monoculturalista, que sempre pensa políticas genéricas para o país e para a sociedade, sem levar em consideração as diversidades socioculturais que os constituem, para serem superadas e equacionadas. Esse é o principal desafio que a política pública enfrenta, com alguns sinais de melhora, de abertura, mas ainda é um enorme gargalo, que eu acho que tem que ser ainda muito trabalhado. 
Um movimento que percebemos visível, principalmente no meio acadêmico, é a presença de estudantes indígenas no ensino superior, que já é forte, é intensa. Percebemos uma vontade dos jovens, das lideranças indígenas, de ingressarem no ensino superior. Como é essa relação entre a educação indígena e o ensino superior? Como vês esse panorama dos indígenas no ensino superior hoje, no Brasil, que é forte na graduação e que já começa a aparecer também, com certa presença destacada, nos mestrados e doutorados, em especializações?

A conquista do ensino superior representa o momento histórico marcante que vivemos hoje, resultado de lutas do movimento indígena e da sociedade brasileira nos últimos anos. É uma dessas conquistas importantes no campo do direito indígena. Eu diria que a chegada dos índios à academia é resultado dessa luta e representa um dos avanços mais importantes. Só para ter uma ideia, o número de indígenas que estão no ensino superior é o mesmo dos que estão no ensino médio - o que é uma coisa extremamente preocupante para o ensino médio. Significa que estamos em uma velocidade enorme de acesso ao ensino superior, mas muito pequena no ensino médio. Eu acho que o forte interesse dos indígenas com o ensino superior mostra esse novo tempo da visão e atitude dos povos indígenas no Brasil. É bom registrar que até há pouco tempo - e pouco tempo que eu digo são 30 anos - não havia essa decisão dos índios pela escola. As comunidades indígenas, em sua grande maioria, não valorizavam a escola. A escola era como se fosse uma assistência do governo ou de suas assessorias, geralmente ONGs, antropólogos ou Igrejas, que ofereciam a escola na aldeia. Nos últimos 30 anos os povos indígenas no Brasil, no meu entendimento, tomaram essa decisão de apostar na educação. E a chegada muito forte à universidade faz parte dessa aposta: escola pode ser um instrumento importante para o presente e para o futuro desses povos, em todos os aspectos, seja para maior interação com o mundo envolvente, com o mundo não indígena de forma mais ampla possível, o que mostra o grande interesse pelo diálogo e por uma convivência, mas também há interesses específicos, como melhorar as condições de vida nas aldeias.

Quando a gente fala com os caciques indígenas ou com os pais dos alunos indígenas, eles são muito práticos no que querem da academia e da escola, que é acesso a conhecimentos, técnicas, tecnologias que facilitem e que os ajudem a enfrentar os desafios na aldeia. Isso é outra coisa que às vezes não se leva 
muito em consideração. Às vezes se desenha a vida na aldeia como uma vida ideal, quase paradisíaca, uma vida boa, uma vida tranquila, mas não é. Viver na aldeia, e isso há milhares de anos, sempre foi enfrentando muitas dificuldades. Muitas vezes com grandes problemas de alimentação, grandes sacrifícios de trabalhos pesados e de altos riscos. Essas dificuldades econômicas de subsistência não existem somente por conta do processo acelerado de desenvolvimento econômico predatório e capitalista, elas sempre existiram muito antes. A vida sazonal dos índios é sempre intercalada de diferentes momentos de precariedade e abundância alimentar, razão pela qual há a prática do nomadismo como busca por melhores espaços de oferta de alimentos. Sempre houve muito esforço e sacrifícios por parte dos povos indígenas para a sobrevivência, do ponto de vista do investimento físico, do trabalho forçado, do trabalho pesado em suas aldeias e territórios. Os povos indígenas almejam melhorar isso, melhorar sua alimentação e as condições de trabalho.

Por exemplo, era muito difícil você trabalhar fazendo roças, derrubando uma árvore com machado de pedra: você levava semanas para derrubar uma árvore. Então é muito mais fácil fazer isso com machado de ferro ou como é hoje em dia em algumas aldeias, de motosserra. As relações socioculturais e econômicas feitas por meio de visitas entre aldeias e povos, que significavam empreender longas e distantes viagens durante semanas ou meses, hoje em dia se fazem até entre aldeias de diferentes municípios, de diferentes estados ou até mesmo entre países, em algumas horas ou dias de carro, barcos ou aviões. Antigamente essas viagens eram feitas a pé, por meios terrestres, ou em canoas por meios fluviais, ao longo de meses e meses, muitas vezes enfrentando chuvas, fome, doenças, acidentes naturais. Hoje pode ser feita com carro, com barco motorizado.

É importante perceber como os povos indígenas têm esse interesse, e é um direito. Portanto, a escola e a universidade entram como um instrumento que pode ajudar a melhorar e facilitar o bem viver dessas comunidades. É importante ter clareza de que não dá para conceber a vida na aldeia como uma vida suficientemente feliz, em que não há nenhuma demanda, nenhuma precariedade, nenhuma dificuldade, como às vezes parece ser. Muitos historiadores e antropólogos românticos ainda alimentam essa visão: os índios não deveriam sair da aldeia porque eles estão felizes na aldeia. Quem diz isso, vá viver 
na aldeia! Vai perceber o quanto o sofrimento é grande. Eu tive essa oportunidade de viver.

Uma das razões pelas quais meus pais, na década de 80 , saíram da aldeia para uma pequena cidade, que é São Gabriel da Cachoeira, foi a dificuldade de criar e sustentar os filhos. Isso porque com a melhoria da saúde e da educação a população cresceu muito. Toda vez que a população cresce, vai piorar as condições de vida, porque a demanda é muito maior pela caça e pela pesca, e a reprodução natural dos recursos, por si só, não garante. Uma das razões de ir para a cidade foi isso, porque a avaliação era essa: é muito melhor a gente ser assalariado na cidade e poder comprar todo dia uma sardinha enlatada, um ovo para comer, do que na aldeia, onde você pode passar dois, três ou quatro dias sem comer nada, porque não tem. O pai de família precisa empreender longos períodos de caça a regiões cada vez mais distantes, e por tempos longos, que às vezes significa 3,4 ou mais dias de caça, durante os quais sua família fica na aldeia totalmente desprovida de qualquer alimento.

O ensino superior é isso. Obviamente que essa é a base da demanda, mas tem outras demandas que são mais sofisticadas, que entram na estratégia muito mais política das lutas dos povos indígenas, como, por exemplo, melhorar a cidadania. Então o acesso às políticas públicas depende desse domínio cada vez maior do mundo da universidade e do mundo escolar, para melhorar as condições de vida nas aldeias e possibilitar que os indígenas não precisem abandonar suas aldeias e terras para se aventurar nas cidades, como vem acontecendo. Os povos indígenas sempre preferem permanecer em suas aldeias e em seus territórios, desde que as condições de vida sejam melhoradas. A educação escolar é uma dessas políticas públicas esperadas nas aldeias e que ajuda a evitar ou diminuir o êxodo indígena, pois ela é uma dessas demandas que os povos indígenas apresentam, e se não é atendida nas terras indígenas, as famílias indígenas vão atrás dela nos centros urbanos.

Mas as outras políticas públicas também são necessárias, como as de saúde e autossustentação. Obviamente que há a luta mais política em vista de um diálogo mais produtivo, mais construtivo com os dirigentes da política pública. Acho que isso é fundamental. É o que os indígenas sempre chamam: "Olha, a gente tem sido até agora muito tutelado, dependente dos brancos, agora precisamos conquistar e exercer a nossa autonomia”. Por trás de todo esse esforço vem o desejo da autonomia. Mas que autonomia? Autonomia política? Não! 
Autonomia de vida, autonomia de viver. Como se enfrenta hoje o problema de saúde? Grande parte do problema de saúde nas aldeias tem a ver com a falta de profissionais da saúde para ir às aldeias. Os médicos brancos dificilmente conseguem ir para as aldeias, mesmo que se paguem salários altíssimos eles não vão. Nesse caso, nós temos que formar nossos médicos. Nós precisamos defender nossas terras e para isso precisamos de advogados, mas dificilmente encontraremos advogado branco e por isso temos que formar nossos advogados indígenas. Nós precisamos melhorar nossa produção econômica na roça, então é importante a gente ter técnicos para ajudar nisso. Eu diria que há, sim, uma estratégia de valorização e de aproveitamento instrumental e estratégico da escola e da universidade para formar esses técnicos. E isso é só um começo.

Uma vez que chegamos à universidade, a decorrência é ocupar a universidade e seguir por diante, porque isso é uma coisa muito boa para os índios e deveria ser uma coisa boa para a universidade também, pois vai diversificando e enriquecimento os conhecimentos. As universidades ainda aproveitam muito pouco dos conhecimentos, da sabedoria que os índios levam consigo para a universidade. Eu não tenho a menor dúvida do inverso: os povos indígenas aproveitam tudo. Eu tenho ouvido falar isso pelo Brasil afora, dos professores que trabalham com os estudantes indígenas. $\mathrm{O}$ interesse que os alunos indígenas apresentam pela sua formação acadêmica é sempre muito maior do que o interesse dos não índios. Eles querem ficar 4 ou 5 anos e aproveitar tudo que podem, porque têm na cabeça que tudo vai servir para ajudar a comunidade deles. A comunidade vai cobrar dele, então ele tem que aproveitar tudo. É claro que muitos não vão voltar para a aldeia, e isso é comum, é natural. Eu não vejo nenhum problema, é um direito e acontece em todas as culturas. Agora, o mesmo não acontece com as universidades, acho que esse tipo de investimento ainda precisa melhorar. Porque se houver reciprocidade no aproveitamento dos diferentes saberes indígenas e não indígenas na academia, todo mundo ganha com isso. Se um dia a gente conseguisse, por exemplo, aproveitar bem complementarmente os conhecimentos dos índios com relação a plantas medicinais e da medicina tradicional com a medicina científica, todo mundo sairia ganhando, índios e não índios. Nossa, que riqueza teríamos! No entanto, não se faz isso. Há desafios nesse sentido.

Mas ainda há outro aspecto importante na conquista do ensino superior pelos povos indígenas, que é a estratégia para o empoderamento político e 
técnico para a própria transformação e qualificação da escola indígena. Se a escola foi, ao longo de todo o período colonial, utilizada pelos colonizadores para dominar os povos indígenas, agora os próprios povos indígenas, por meio de seus professores, gestores e técnicos indígenas, devem transformar essa escola de acordo com suas demandas, projetos presentes e futuros, estratégias e interesses coletivos. Acredito muito que os professores indígenas graduados, mestres e doutores irão gradualmente transformando, moldando e aperfeiçoando as atuais escolas indígenas em verdadeiros instrumentos de luta e de defesa de seus direitos, a partir de novas formas de organização curricular, tendo como base as metodologias e pedagogias indígenas.

Considerando então as possibilidades de a sociedade não indígena aprender com e sobre os povos indígenas e em relação à Lei Federal 11.645/2008, uma lei que implica muito os professores de História do Brasil, como vês a implementação dessa lei? Como ela se relaciona com o movimento indígena? De alguma forma, sua implementação pode repercutir também na relação entre povos indígenas e não indígenas. Nesse sentido, o que dirias?

Eu acho que a Lei 11.645 é um instrumento fundamental para combater principalmente o preconceito e a discriminação, porque estou convencido de que a origem principal da discriminação e do preconceito é a ignorância, o desconhecimento. Não se pode respeitar e valorizar o que não se conhece. $\mathrm{Ou}$ pior ainda, não se pode respeitar ou valorizar o que se conhece de forma deturpada, equivocada e pré-conceitualmente. Nesse sentido, a primeira tarefa é desconstruir pré-conceitos históricos plantados nas mentes das pessoas ao longo de centenas de anos de colonização. Essa desconstrução de pré-conceitos é uma verdadeira deseducação, ou seja, aprender a reconhecer os erros aprendidos na própria escola. Só depois do processo de deseducação será mais fácil uma nova reeducação com base em novos princípios e visões de mundo capazes de construir uma nova realidade social, cultural, econômica, política e espiritual menos eurocêntrica e com lugares para todos os povos, culturas e saberes com os quais a escola trabalha, os quais ela precisa valorizar e dar conta.

A escola é a instituição e o lugar privilegiado e estratégico para reduzir ou eliminar a intolerância, o preconceito, a discriminação e o racismo entre pessoas e povos. A Lei 11.645 é, portanto, uma excelente oportunidade e possibilidade para isso. Agora, nós temos alguns desafios. Embora seja um instrumento 
importante, nós não estávamos preparados para isso porque veio um pouco cedo, do ponto de vista da construção mental, do imaginário. Veio mais como possibilidade. "Nós" quem? Tanto nós indígenas, quanto a sociedade não indígena. Isso foi uma luta aproveitada do movimento negro, pela articulação afrodescendente, e a gente conquistou esse direito muito importante. Espero resultados mais concretos em médio prazo. Contudo, é fundamental, porque vai ajudar ou já está ajudando a oferecer mais informações e conhecimentos sobre os povos indígenas de forma mais correta. No campo da educação, em termos de material didático, isso é fundamental e deve ser muito trabalhado.

Temos grandes desafios: primeiro, não temos materiais didáticos educativos! E me parece que é difícil produzir material didático para atender essa orientação normativa, pela própria complexidade que é. Veja: nós estamos falando de informações, de conhecimentos sobre os índios, para não índios. Então, o primeiro desafio é como os povos indígenas vão se apropriar dessa ferramenta para divulgar seus conhecimentos, seus valores, suas culturas e tradições. Ainda não vejo o movimento indígena mobilizado para isso. Essa é a principal dificuldade. A primeira pergunta é: "O que os povos indígenas querem que os não índios saibam deles?”. Isso já é um enorme problema, porque teremos muitas dificuldades para os próprios índios definirem isso, diante da grande diversidade de povos, realidades locais e contextos históricos. São os índios que devem definir o que querem e como querem ser conhecidos pela sociedade nacional. "Que tipo de conhecimento querem divulgar?" Aos povos indígenas, muitos conhecimentos seus não interessam que os brancos fiquem sabendo, pois nem internamente são de domínio público, como são os conhecimentos dos pajés. Teremos muitas dificuldades para classificar quais são os conhecimentos que podem ser levados ao conhecimento dos não índios.

O segundo desafio é a produção de material de divulgação. Nesse nível, a experiência dos últimos anos no campo da produção de material didático foi muita na área do letramento, da alfabetização. Temos hoje mais de duzentos títulos, sendo oficiais e reconhecidos pelo Ministério da Educação como material didático sobre indígenas para escolas indígenas, mas tudo na área do letramento. Ocorre que para a orientação da Lei 11.645 terão que ser materiais didáticos bem mais trabalhados, porque fundamentalmente são para atender a educação básica e fortemente o ensino médio, onde a juventude tem mais interesse no tema. É muito difícil produzir isso. Acho que o Ministério da 
Educação, os estados, por pressão do Ministério Público, estão se virando para ver se conseguem esse material didático. Sei que o Ministério da Educação está se esforçando pelo menos para oferecer um primeiro kit para os sistemas de ensino, que trate desse tema. Já tem alguns materiais que podem ser mais bem aproveitados. Ainda não são materiais especificamente pensados para isso, mas que já serviriam: alguns mapas da etno-história, alguns livros que falam dos processos de formação de professores e alguns que tratam da realidade mais geral dos povos indígenas e que já podem ser utilizados. Mas eu acho que só em médio prazo teremos mais materiais didáticos para isso. E só com bons materiais didáticos na mão das escolas dos não índios, de fato, que os alunos não indígenas poderão ter acesso a esse material, com maior qualidade e, aí esperar impactos e resultados mais positivos. Mas sem dúvida nenhuma é um instrumento extremamente importante que temos que abraçar com seriedade, porque é o caminho para diminuir a discriminação e o preconceito, oferecendo, principalmente à nova geração de cidadãos das escolas, jovens e crianças, informações qualificadas sobre os povos indígenas de forma correta. É também a forma mais prática de desmistificar e desconstruir alguns estereótipos que foram criados, inclusive na escola, por meio de livros didáticos pensados do ponto de vista dos colonizadores e dominadores.

Uma liderança Guarani, falando da implementação da Lei 11.645/2008, anunciou a necessidade de três movimentos: (1) criar uma sensibilização entre os professores para a temática indígena e (2) efetivar um movimento de estudo da história e da cultura indígena - assim como se estuda a história de outros povos -, mas ele apontou um terceiro movimento, sobre o qual gostaria de ouvir tua opinião: a história indígena contada pelos próprios indígenas. Nesse sentido, poderíamos considerar os estudantes indígenas no ensino superior, nos cursos de História. Como avalias essa perspectiva, que leva em conta a autoria indígena e a formação de professores?

O que você falou é fundamental por ser um dos primeiros desafios, que é a formação de professores. O Brasil enfrenta um problema histórico e macroestrutural em termos de formação de professores. Pois se há uma fraqueza muito grande na política brasileira com relação à educação de modo geral, é a formação de professores. Para que a Lei 11.645 ganhe efetividade esse é o ponto de partida, porque não adianta trabalhar material didático se não trabalhar a 
formação desses profissionais. O Brasil tem dois instrumentos, um é a formação inicial que habilita o professor indígena, tanto no nível do magistério médio quanto no magistério superior, e o outro é a formação continuada. Tem que trabalhar isso. Agora, isso é um processo cultural grande, que tem que ser adequado, transformado. Para isso o primeiro passo é pensar os processos de formação de professores com a organização curricular voltada para atender a perspectiva da Lei 11.645, ou seja, incluir a história indígena, os conhecimentos e as realidades indígenas. Eu acho que essa ideia de produção da história contada pelos próprios índios, sem dúvida nenhuma, é o melhor caminho, pela legitimidade que o sustenta. Agora, os índios que estão na academia são fundamentais para isso, porque têm que se articular para formar redes de estudos e de pesquisas, inclusive de elaboração de material didático e paradidático. Agora, não pode ser desvinculado das comunidades, e esse é outro desafio. Eu acho que isso também melindra mesmo quem é indígena. Porque, por exemplo, se um grupo de professores indígenas de determinado povo forma uma rede, forma um grupo de estudo, de pesquisa e começa a escrever, por exemplo, vai escrever sobre o seu povo. Você deu o exemplo do povo Guarani. Mas vai falar de que Guarani? Você tem Guarani em sete, oito estados ou mais ainda, em três ou quatro países. Pode-se falar do Guarani como um todo? Por exemplo, o Guarani de uma aldeia só vai poder falar do Guarani daquela aldeia.

Estou falando isso em termos de dificuldade de dar conta da diversidade interna dos povos indígenas a partir das políticas públicas. O ideal seria que cada aldeia pudesse produzir o seu material. Como é que ele quer contar a sua história para os não índios? O grande problema é que isso teria que ser trabalhado de aldeia por aldeia, porque eu vivi algumas experiências com meu próprio povo Baniwa. Nenhum Baniwa ou nenhum grupo Baniwa hoje tem autorização ou legitimidade para falar sobre os Baniwa. E os Baniwa estão dispersos na Colômbia, na Venezuela e no Brasil. Eu vi isso acontecer muito naquela região.

O Instituto Sócio Ambiental (ISA) ajudou a elaborar vários livros muito bons que capacitaram e formaram grupos de indígenas. Os índios escreveram e publicaram suas histórias e mitos. Quando publicados, eu nunca vi esses livros ganharem vida. Ficaram guardados. Por quê? Imediatamente os outros grupos diziam “Isso aí não é assim, não foi contado assim, isso aí é do clã tal, do grupo tal...”. Então existem essas dificuldades, é preciso que os que trabalham com política pública entendam isso, para não frustrar os outros e não se frustrarem. 
Não é um caminho simples trabalhar com a diversidade. Agora, o caminho é esse, formar redes de trabalho. Tem que considerar os contornos geográficos, políticos, étnicos para atuar nesse campo. O que estou dizendo com isso é que é um trabalho bonito, mas que é muito complexo. A gente tem que ter muita paciência no trabalho, porque só com muito tempo poderemos avançar, pois não é uma coisa que dá para tomar certas medidas de cima para baixo, de uma hora para a outra, mesmo envolvendo indígenas. A referência dos indígenas na universidade, sem dúvida, é fundamental, como sujeitos, agentes e lideranças futuras do movimento indígena e da luta dos povos indígenas. Eu não tenho a menor dúvida disso, da força e da responsabilidade que vão ter. Daí uma grande preocupação nos seus processos de formação. Quanto mais as universidades colaborarem aperfeiçoando, adequando, dando qualidade à formação - que não é apenas a qualidade acadêmica, interna, mas associar isso aos diferentes processos que eles vivem junto às suas comunidades.

Do ponto de vista pragmático, podemos dizer que somente os indígenas têm a legitimidade de decidir sobre o conteúdo da história indígena, como sujeitos, portanto, do seu ponto de vista. Mas para que isso aconteça é necessário construir condições, principalmente no ambiente das universidades, onde se encontra acumulada uma grande variedade de riquíssimos acervos sobre a história indígena, que precisam ser apropriados pelos indígenas e reinterpretados por eles. Outro apoio necessário é do poder público, ou seja, dos sistemas oficiais de ensino, para garantir as condições técnicas e financeiras para a produção e divulgação em escala desses materiais.

Vejo, portanto, uma rede em forma de tripé para garantir a efetividades desse propósito. $\mathrm{O}$ primeiro elemento é o protagonismo indígena tendo como referência os estudantes e pesquisadores indígenas conectados às suas comunidades. $\mathrm{O}$ segundo elemento é a academia incluindo necessariamente os pesquisadores que trabalham com os povos indígenas, como parceiros, aliados e assessores no empreendimento. O terceiro elemento é o poder público, por meio do apoio técnico e financeiro, mas não só isso, com o compromisso político de garantir o cumprimento da norma em todas as escolas, por meio de formação de professores, de distribuição de materiais didáticos e, principalmente, por meio do convencimento dos sistemas de ensino no cumprimento de suas tarefas. 
Inclusive para pensar sua identidade, porque no meio da academia essa identidade também é demandada.

Exato. A academia é um espaço extremamente rico e aberto. Nesse sentido, acho importante, porque a academia permite fazer muita coisa. Não é como uma ONG ou como uma Igreja, que são completamente diferentes, fechadas, você não consegue fazer nada a não ser dentro das ideologias e doutrinas que impõem. A academia é aberta, assim como você vai encontrar muitos que não querem saber de índio ou que são anti-indígenas, você vai encontrar pessoas sensíveis e que podem estabelecer diálogos e processos interessantes de construção. Isso tem que ser valorizado, e os jovens indígenas vão com muita sede para isso. Eu acho que em breve vamos ter os primeiros resultados, e espero que sejam bem positivos para essa geração de jovens acadêmicos que são muitos. Hoje se estima em dez mil. É muita gente! Espero que isso ajude a fortalecer a luta dos índios, não só pela identidade e cultura, mas também na luta pelos direitos coletivos dos povos indígenas e de outros segmentos sociais historicamente excluídos. A academia ajuda a entender melhor todo o processo histórico vivido e enfrentado pelos povos indígenas, e nesse mergulho histórico, analítico e crítico, em geral os jovens indígenas se reencontram, se reconstituem e se consolidam consciente e criticamente enquanto membros pertencentes a uma história, a uma coletividade étnica particular e a um projeto de sociedade local, regional, nacional e planetário.

\section{Mais alguma coisa que achas relevante dizer? Uma perspectiva para o futuro?}

A educação escolar indígena vive hoje um momento muito interessante. Foram duas ou três décadas de laboratório, de experimentação de modelos, de processos educativos que pudessem ir além das experiências coloniais de escola. E essa diversificação de experiências, que em alguns lugares são chamados de escolas pilotos, de escolas alternativas, de escolas indígenas, de escolas diferenciadas, trouxe muita aprendizagem. Nós estamos vivendo agora no Brasil um momento de consolidação dessas experiências projetando o futuro. Vimos que algumas possibilidades são muito idealistas e, por isso, não se sustentam do ponto de vista prático, de como as comunidades indígenas pensam e como elas querem construir seus processos educativos, escolares ou não. Nessa 
consolidação eu acho que tem algumas coisas muito interessantes. Uma delas, trazida pela única Conferência Nacional de Educação Escolar Indígena da história do Brasil, que foi realizada em Brasília em 2009, é que algumas políticas precisam ser aprofundadas. Por exemplo, essa linha de estruturação das escolas indígenas, agora com esse novo viés, da autonomia na gestão, do protagonismo indígena, cada vez mais vem fortalecendo as pedagogias indígenas, os processos próprios de aprendizagem, o que é fundamental. Mas há uma necessidade de melhor estruturação dessa política por meio de algumas propostas: uma é organizar melhor o financiamento. O financiamento da educação escolar é crescente nos últimos anos, mas com pouco efeito na ponta, então isso precisa ser adequado. O segundo é uma novidade na política da educação, que é a ideia da escola autônoma e diferente. Percebemos que os sistemas de ensino que nós temos hoje não são capazes de atender isso. Não é por vontade, é pelas condições técnicas e políticas. Os sistemas de ensino dos municípios, dos estados e da União nunca foram pensados para dar conta dessa diversidade, mas sim para pensar a nação, o município, o estado. Daí cada vez mais todo mundo é convencido de que há a necessidade de pensar uma organização de sistema próprio de educação escolar indígena.

\section{Isso dialoga com a perspectiva dos territórios étnico-educacionais...}

Exatamente. Na perspectiva de pensar um sistema próprio para a educação escolar indígena precisamos superar a dependência dos sistemas instalados, que são os sistemas dos municípios, dos estados e da União, para criar outro sistema específico, porque a própria legislação diz: "São garantidos aos índios os processos próprios de ensino-aprendizagem”. Esses processos próprios precisam de um sistema próprio, senão cai-se sempre na contradição e na dicotomia oferecida pelos sistemas tradicionais dos brancos, que podem ser interessantes para os brancos, mas não para os índios. Uma base para esse sistema próprio são os territórios etnoeducacionais quando criam uma nova forma de configuração do planejamento e da forma de pensar e organizar os serviços públicos educacionais voltados para as comunidades indígenas.

Nessa nova configuração do planejamento e gestão da política de educação escolar indígena, devem-se levar em consideração as configurações etnoterritoriais dos povos indígenas que não correspondem às configurações político-territoriais dos municípios, dos estados e da União, ou seja, as formas 
'como' e 'com quem' eles organizam suas relações, suas demandas, suas estratégias e suas alianças e parcerias. Os territórios etnoeducacionais apontam claramente para o reconhecimento das tão sonhadas autonomias indígenas em seus territórios, na hora de pensar, organizar e implementar políticas públicas educacionais, com envolvimento, participação, protagonismo e controle dos beneficiários indígenas. Como é que se pode trabalhar a especificidade do direito, da cultura, da tradição e dos processos educativos próprios dos povos indígenas, dentro da configuração dos estados e dos municípios? A ideia é que se tenha uma nova configuração espaço-tempo, uma nova configuração de sistema jurídico-administrativo, de normas, de regras e de financiamento público. Portanto, a meta em médio e longo prazo é constituir esse novo sistema, que é uma longa batalha a acontecer, que curiosamente, como eu disse, a política educacional brasileira é uma das políticas mais conservadoras no campo das políticas públicas no Brasil. Quem trabalha nesse campo sabe perfeitamente que é. Por exemplo, a política de saúde tem muitos problemas, mas a política de saúde resolveu essa coisa de sistema há 20 anos. A saúde indígena é um sistema próprio, lógico que articulado ao Sistema Único de Saúde, porque é um sistema ou subsistema dentro da estrutura do Estado, mas com financiamento próprio e com sua organização espaço-temporal própria, que são os Distritos Sanitários. Para isso é necessário criar e organizar novos processos administrativos, para atender as realidades específicas das comunidades e terras indígenas. Processos de contratação de professores indígenas, de construção de escolas indígenas, de serviços de transporte escolar de alunos indígenas não podem ser os mesmos processos utilizados para as escolas urbanas e rurais de não indígenas. Se isso não for mudado, os povos indígenas continuarão sendo excluídos das políticas, e suas escolas e processos educativos ficarão situados em níveis baixíssimos de indicadores de qualidade, como continua sendo. Há ainda muita resistência, porque o conservadorismo da elite que pensa a educação é fenomenal. Se você pensar uma educação diferenciada, para eles você estará questionando a soberania nacional. Não há coisa mais ridícula, mais conservadora e mais atrasada nesse debate, mas é assim que a nossa elite da educação brasileira pensa e age. Vai ser, portanto, uma luta longa. Por outro lado, no Ministério da Educação já tem gente que acredita e que concorda com isso, então vai ser uma boa briga nos próximos anos.

Entrevista recebida em 20 de junho de 2012. Aprovada em 1ํ de setembro de 2012. 